\title{
Factors affecting job performance of airline operations employees in Thailand
}

\author{
Nisara Paethrangsi ${ }^{1,{ }^{*}}$ and Tawee Jamjumrus ${ }^{1}$ \\ ${ }^{1}$ Suan Sunandha Rajabhat University, Thailand
}

\begin{abstract}
Job performance behaviour of employee is a critical driver of organization performance. Airline operations employees namely, pilots, cabin attendants and ground service agents can increase organizational effectiveness. This research analysed the effect of individual characteristics, organization behaviour, learning and development and compensation on operations employees performance. The purposes of this study were (1) to identify factors affecting job performance of airline operations employees in the context of Thailand, (2) to evaluate success factor categories with employee job performance, (3) to explore significant difference between ranking results from two certain groups of respondents. A random sample of 400 respondents divided into two groups, group one200 experienced employees (60 pilots, 70 flight attendants and 70 ground service agents) from five airlines in Thailand, group two- 200 HR strategic experts and HR university lecturers completed an online survey. Research concluded that rank order views from both groups were not much different. It showed that job performance is highly associated with organization behaviour, which is motivated by organization culture, organization structure, workplace ambience and leadership and teamwork process. HR experts rated the importance of learning and development in the second order while employees rated the importance of compensation in the second place and perceived learning and development as the least important.
\end{abstract}

\section{Introduction}

Thai government policies promoting Thailand as a regional aviation hub, by supporting and creating development approaches, such as infrastructure readiness and aviation networks, tourists creating and launching Thailand is the hub for connecting flights with foreign countries. Thailand, established policies and measure to increase demand for air travel, established measures and guidelines to cope with the impact on the national economy. Government has enhanced the growth of aviation's in three areas they are including, enhancing civil aviation authorities related civilian air transportation to monitor aviation industry to meet ICAO standard, systematically employed aviation liberalization policy. In addition, the rail networks and land networks have been extended to facilitate passenger travel and logistics for air transport, also extension of the metro system to the airports. Thai government has conducted a study of the global economy, international

\footnotetext{
*Corresponding author: nisara.pa@ssru.ac.th
} 
political relations related to aviation policy, potential of neighbouring countries on the readiness of airports and facilities to expand transportation and tourist attractions, which affecting large number of passengers' travels to and from Thailand, to attract many airlines in choosing Thailand as a hub of Asia. In 2020, Thai economic has been slow down continuously and its performance was further below nation's potential. This is due to the global COVID-19 pandemic, which severely affects the tourism business and domestic employment [1].

Low-cost airlines (LCCs) in Thailand are facing internal pressure and new challenges from outside especially the post-COVID-19 situation, the restrictions on the diseases have affected the reduction of airlines traffic both cargo and passenger. Nevertheless, social distancing measure forces an airline to reduce the number of passengers on each flight, resulting in higher costs and massive declining demand for all airlines. Thai LCCS have adapted themselves to remain their cabin load factors and keep survive operations. Nearly all airline operations employees have been forced to reduce working day for company cost savings. However, retaining valuable resources is essential to match market demand when operations are resumed. IATA estimated that in 2021 demand for passenger travel and air cargo will rise sharply (see figure 1).

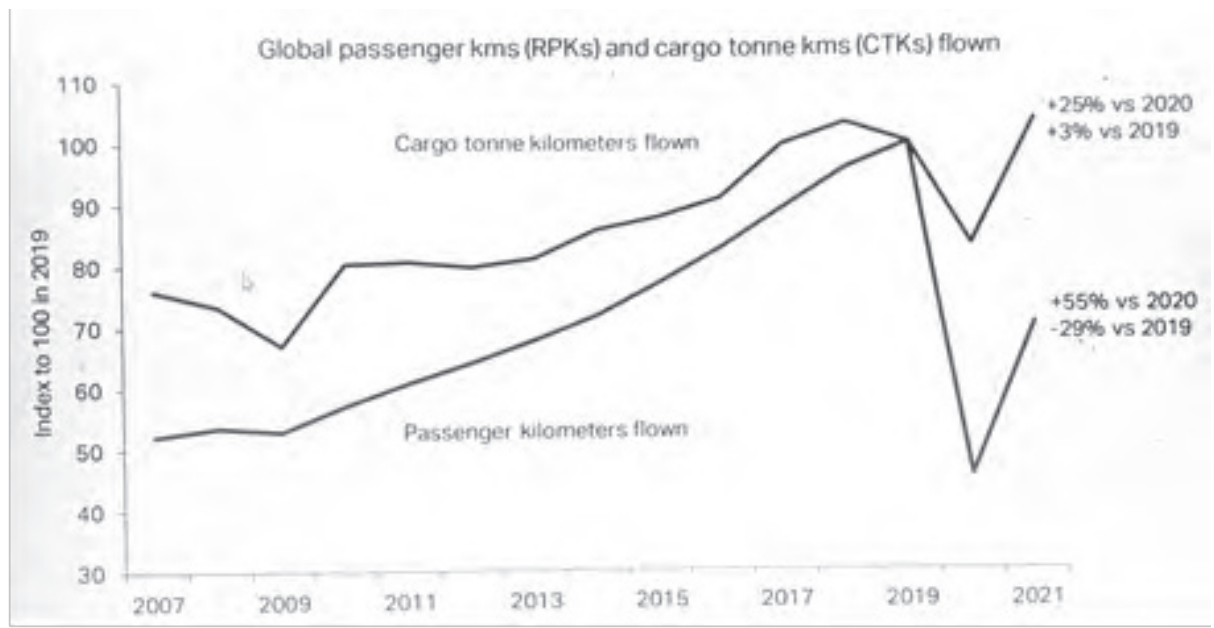

Fig. 1. Forecast demand for global passenger travel (RPKs) and cargo transport (CTKs) in 2021. Source: International Air Transport Association Statistics [2].

\section{Theoretical and Literature Review}

Demand for pilots and airline employees will increase by the end of 2021, more than 260,000 new pilots will be needed worldwide over the next 10 years [3]. The airline business will be recovered quicker than currently IATA estimated because the key drivers of vaccines, fiscal stimulus, and monetary easing policy. Employee behaviour is considered as related to job performance and be able to create the values that contribute, either positively or negatively, to organizational goal accomplishment [4,5].

Colquitt, Lepine, Wesson [6] categorized employee job performance which fits into the organizational goal into three broad categories, they are 1) routine task performance that employees perform works as habit for example the duty of flight attendants when demonstrate the live safety briefing and the ground service agent assign seats to passengers at check in counter, 2) adaptive task performance is concerned employees respond to task demand that are unusual for example, when a flight delay and ground service agents need to 
handle complaints from passengers or arrange the new flight for customers. And 3) creative task performance involves the ability of employee individually to create ideas or outcomes that fit and useful to the firm's goal. Most of organization realized the important relation between employee work performance and organizational performance. There are several effective to measure employee performance such as managing by objective, behaviourally anchored rating scales, 360-degree feedback, forced ranking and social networking systems. $[7,8]$.

Jamjamroon \& Somsuk [9] studied key success factors for flight operations of Nok Airlines and revealed that there are four areas of key success categories that segregated to managerial resources, human resources, technological resources and financial resources. Research concluded that among fourteen critical success factors, the most important factor was employees who have moral virtues follow by the factor of knowledgeable and experienced persons in the particular positions.

Researcher also recommended developing employee with morality, ethics, meaning there is an organizational culture that emphasizes on employees being diligent, patient, sacrifice, honest, and committed to firm's interests rather than personal interests. The culture of effective working should be adopted for profitability.

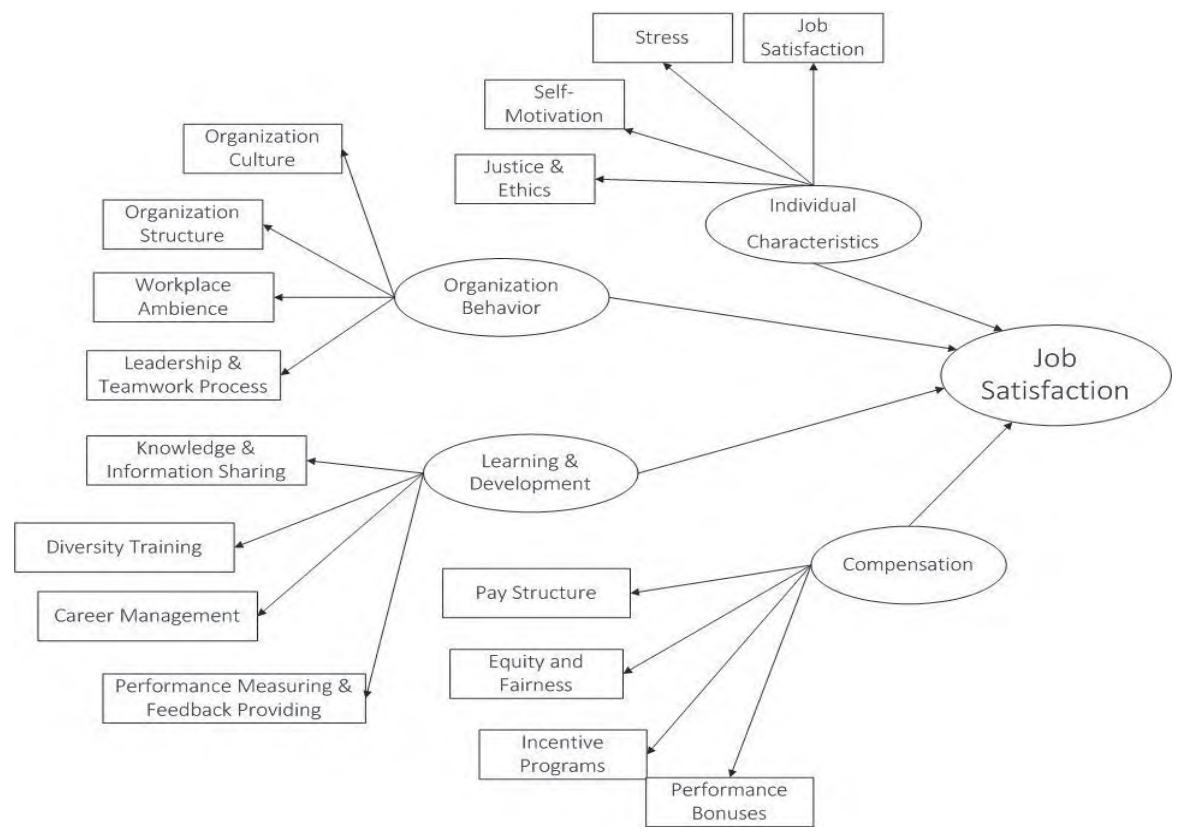

Fig. 2. Conceptual Framework of the research.

\section{Research Methodologies}

This mixed method study addresses the question that, what factor is the most significant affects employee job performance. Researcher examined the relationships of Individual characteristics, organization behaviour, learning and development and compensation with job performance, which the proposed factor categories play roles in predicting employee performance.

Success factors, employees' job performance and organizational goal have been reviewed from literature and researches then conduct in-depth interviews with twelve managements in airline business. Quantitative study used questionnaires on population of 
200 members of airlines employees in Thailand (employees) and 200 Human Resource strategy personnel (HR experts).

Respondents were separated into two groups, which they are (1) group of airline operation employees who are 60 pilots, 70 flight attendants and another 70 ground service agents and (2) a group of HR experts which included 200 human resource managers, supervisors and lecturers in hospitality service and consulting company. The respondents were asked to sort the sixteen factors into nine levels of significance according to the perception of high relation to job performance. Nine significant levels at that the important" (8) to least important (0), with seven degrees of importance between the extremes 7 through 1 [10], see figure 3 .

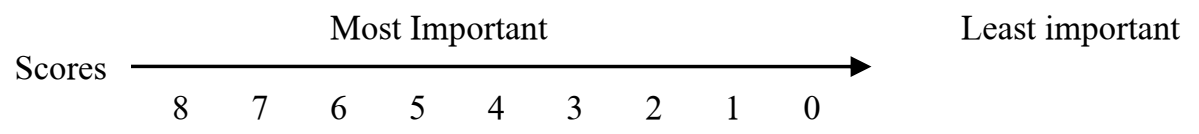

Fig. 3. Level of variables importance comparison.

Sixteen variables in four factors categories were ranked-ordered from "Most Important" (8) to "Least Important" (0), with seven degrees of importance between these extremes (7 through 1). To facilitate the ranking, each respondent was given a set of instructions that described the process of ranking. The ratings of the 400 respondents were consolidated and processed to determine the mean for each factor. Then check the significant difference factors which were ranked between two groups. The category of individual characteristics is job satisfaction, stress, self-motivation, justice and ethics, which are key drivers of job performance and organizational success $[6,11,12]$.

Hence, airline employee personality and organization culture reflects the way employees behave at work [13]. For job abilities, it comes from both people mentalities and physical abilities such as cheerfulness, enthusiasm, strength and endurance.

Registe [14] studied individual work performance: A cross- sectorial, human services study of employees' work performance within the business office environment, research indicated that individual stresses has been shown having a close relationship with job performance in reverse. Research also demonstrated that job satisfaction, employee personal stress, self-motivation and human justice, trust and ethics associated with increased affective commitment, job satisfaction and job performance.

For category of organizational behaviour concerned with organization culture, organization structure, workplace ambience and leadership and teamwork engage people of happiness. Ghujil [15] examined the relationship between ethical leadership and job performance through job satisfaction, employee organizational commitment, and employee trust, and confirmed that, there was a significant positive relationship between ethical leadership and job performance.

A firm fosters a positive, energetic work environment lead to morale in the office gets a boost. Organization provides equal employment opportunity, pleasant and safe workplace ambience engage high potential employees and translate into results of clients perceive the employees are consulted and dependable and relate to them. In addition, working in a team can motivate employees by making work more interesting and significant [16].

A category of Learning and development are combined with tacit and explicit knowledge that are important to employee and organization. A company that invest in employee training and development will earn high return outcomes. The relevant training outcomes are the ones related to the organization's goals and overall business performance [6]. Learning and development are included knowledge and information sharing, diversity training, career management and the variable of performance measuring \& feedback providing. Compensation category, pay is a powerful tool for airlines to drive performance reach firm's goals. Pay has direct impact on employee attitudes and behaviours. 
Rewarding in a form of money and others can engage employees' interests with the organization's goals. Employees care about policies affecting earnings because that affects their income and standard of living [17]. Employees also care about the fairness compared with what others earn. They attach great importance to pay decisions when they evaluate their relationship with their employer are pay structure, equity and fairness, incentive programs and performance bonuses because employees consider compensation as an evident of success.

\section{Results and Analysis}

To test the validity of the proxy in this study, the variables in each category have been done though quantitative method. The respondents rating results provide evidence that proposed success factor series affect job performance of airline operation employee (see table 1)

Table 1. A comparison between the two groups (HR experts and airline employees).

\begin{tabular}{|l|c|c|c|c|c|c|}
\hline \multirow{2}{*}{$\begin{array}{c}\text { Category of } \\
\text { success Factors }\end{array}$} & \multicolumn{2}{|c|}{ HR experts } & \multicolumn{2}{c|}{ Employees } & \multicolumn{2}{c|}{ Two groups } \\
\cline { 2 - 7 } & Weights & Ranking & weights & Ranking & Weights & Ranking \\
\hline $\begin{array}{l}\text { Individual } \\
\text { Characteristics }\end{array}$ & 0.160 & 4 & 0.243 & 3 & 0.202 & 4 \\
\hline $\begin{array}{l}\text { Organization } \\
\text { Behavior }\end{array}$ & 0.335 & 1 & 0.315 & 1 & 0.325 & 1 \\
\hline $\begin{array}{l}\text { Learning \& } \\
\text { Development }\end{array}$ & 0.295 & 2 & 0.209 & 4 & 0.252 & 2 \\
\hline Compensation & 0.210 & 3 & 0.233 & 2 & 0.221 & 3 \\
\hline
\end{tabular}

Although the degree of importance of each category is vary, group of HR experts sequent rated the most important factor category to organization behaviour follow by learning \& development, compensation and individual characteristics. Similarly, the group of employees rated the organization behaviour as the most important. Except organization behaviour, employees rated compensation as more important than others. No doubt that learning \& development was perceived least significant from employees.

\section{Conclusions}

There are four categories of success factors which including sixteen factors affecting job performance of airline operations employees. These factors are job satisfaction, stress, selfmotivation and justice and ethics represent the individual characteristics category. The categories of organizational behaviour combine with four factors and they are organization culture organization structure, workplace ambience and leadership and teamwork represent.

The categories of learning and development consist of knowledge and information sharing, diversity training, career management and performance measuring \& feedback provides represents. Pay structure, equity and fairness, incentive programs and performance bonuses factors represent the compensation category. The ranking order based on two respondents groups' views can be conclude as follows; the significance categories of factors are arranged as (1) organization behaviour (weight is 0.325 ). Follow by (2) learning \& development (weight is 0.252), (3) the compensation (weight is 0.0 .221 ), and (4) category of individual characteristics was rated the least important, (weight is 0.202). 


\section{Recommendations and Future Works}

Suggestive policy recommendations can be drawn from this study is, airline operations employees can perform highly in their tasks depends on not only self-efficacy, company training courses, compensation but also on supporting of effective organization behaviour for instance, strong corporate culture, trusting climate, pleasant workplace ambience and organization leadership and teamwork process. Future research should continue analyse the holistic accomplishment of airline business.

\section{References}

1. Thai Economic (Bank of Thailand, BOT, 2020)

2. B. Pearce, IATA Statistics (2020)

3. Pilot career news (CAE, 2020)

4. G. Maeritz, Eissa, Appl. Psycho. 97, 343-359 (2012)

5. M. Ermilova et al., Opcion 34(17), 1074-1087 (2018)

6. J.A. Colquitt, J.A. Lepine, M.J. Wesson, Organizational Behavior; Improving Performance and commitment in the Workplace (McGraw-Hill, New York, 2019)

7. Noe et al., Fundamentals of Human Resource Management (McGraw-Hill, The United States, 2011)

8. H. Van et al., Intern. J. of Energy Economics and Policy 8(4), 21-27 (2018)

9. S. Jeamjamroon, N. Som Suk, EAU Heritage 10(2), 160-174 (2016)

10. W. Stephenson, The study of behavior; Q-technique and Its Methodologyv (The University of Chicago Press, Chicago, 1953)

11. H. Mai et al., Intern. J. of Recent Technology and Engineering 8(2.11), 3876-3882 (2019)

12. K. Kankaew, E3S web of Conferences 175, 13033 (2020)

13. N. Paethrangsi, The Inter. Academic Multi. R.Conference in Malta (2020)

14. B. Registe, The Chicago School of Professional Psycho. ProQuest Dissertations and Theses (2016)

15. H.S. Ghujil, Alliant International Université (2020)

16. A. Tran et al., Intern. J. of Recent Technology and Engineering 8(2.11), 3883-3888 (2019)

17. R.A. Noe, J.R. Hollenbeck, B. Gerhart, P.M. Wright, Human Resource Management: Gaining A Competitive Advantage (McGraw-Hill, 2017) 